\title{
Barriers to and driving forces for industrial energy efficiency improvements in African industries: a case study of Ghana's largest industrial area
}

Raphael Wentemi Apeaning and Patrik Thollander

\author{
Linköping University Post Print
}

\section{Tweet}

N.B.: When citing this work, cite the original article.

Original Publication:

Raphael Wentemi Apeaning and Patrik Thollander, Barriers to and driving forces for industrial energy efficiency improvements in African industries: a case study of Ghana's largest industrial area, 2013, Journal of Cleaner Production, (53), 204-213.

http://dx.doi.org/10.1016/j.jclepro,2013.04.003

Copyright: Elsevier

http://www.elsevier.com/

Postprint available at: Linköping University Electronic Press

http://urn.kb.se/resolve?urn=urn:nbn:se:liu:diva-96168 


\title{
Barriers to and driving forces for industrial energy efficiency improvements in African industries - a case study of Ghana's largest industrial area
}

\author{
Raphael Wentemi Apeaning*, Patrik Thollander \\ Department of Management and Engineering, Linköping University, SE-581 83 \\ Linköping, Sweden
}

\begin{abstract}
Barriers to industrial energy efficiency improvements in developing countries are more pronounced due to the existence of factors like weak energy policy frameworks, financial constraints, weak information systems and many more. This study is an explorative and qualitative research aimed at enhancing the knowledge of industrial energy efficiency and management strategies in Ghana, by investigating the barriers to and the driving forces for the implementation of energy efficiency measures in Ghana's largest industrial area. Results from the study revealed that energy is poorly managed in the various industries and that there is an energy efficiency gap resulting from the low implementation of energy efficiency measures. In addition, the study revealed that the most important factors impeding the implementation of cost effective energy efficiency technologies in the firms are principally economic (or market) barriers like "lack of budget funding" and "access to capital". The study also shows that these economic
\end{abstract}


barriers are linked to the lack of adequate government framework for industrial energy efficiency. The study also revealed that market factors related to "cost reductions resulting from lowered energy use" and "threats of rising energy prices" are the most important drivers for implementing energy efficiency measures or technologies.

Keywords: Energy efficiency; barriers; drivers; energy management practices; energy efficiency gap; industry; developing countries; Africa; Ghana.

\section{Introduction}

Unlocking the global industrial energy efficiency potential is considered as a cost effective means of reducing global fossil fuel consumption, mitigating greenhouse gas emission, improving energy supply security and ensuring a sustainable industrial development (IPCC, 2007; UNIDO, 2011). Despite the existence of cost effective industrial energy efficiency measures, studies indicate that these measures are not always implemented, due to the prevalence of critical limiting factors called barriers (Rohdin et al., 2007). The industrial "energy efficiency gap ${ }^{1}$ ” in developing regions is normally attributed to a combination of market failures and barriers like informational barriers and financial barriers (UNIDO, 2011; Compton, 2011). Although these existing barriers (industrial energy efficiency) in developing countries are similar to developed countries (UNIDO, 2011), the lack of adequate policy frameworks, fragile economies, poor energy infrastructure, among others, makes the existence of these barriers more pronounced in developing regions (Compton, 2011).

Ghana's dedication to industrial energy efficiency improvement dates back to 1987, when the government initiated an "Industrial Energy Rationalization Program" (ESMAP, 1992), in an 
effort to boost the industrial sector's resilience to energy supply deficiencies (like the irregular, unreliable and frequent interruption of energy supply) (EC, 2006a). Since then several other programs have been initiated with the same aim of improving and building capacity for industrial energy efficiency improvement in Ghana. However, these efforts to date have not yielded any sustainable adoption of cost effective industrial energy efficiency practices in Ghana, owing to a number of barriers in the Ghanaian energy market (MoEn, 2010).

The existence of these barriers offers justification for further intervention from government authorities and policy makers to bridge the efficiency gap, by formulating more innovative and comprehensive schemes to boost the energy service market. Nevertheless, for any particular policy or intervention to succeed, a sound understanding of the barriers and the driving forces has to be addressed (Golove and Eto, 1996; Trianni et al., 2012; Thollander and Palm, 2012). It is in this respect that the study was aimed at investigating the barriers and the forces driving industrial energy efficiency improvements in Ghana by conducting a case study of the country's largest industrial area, and further analysing its industrial energy management practices. The research questions pertaining to the study were divided into five major sections:

- Is there an energy efficiency gap in Ghanaian industries?

And if so:

- What are the barriers inhibiting the implementation of cost-effective energy efficiency measures in Ghanaian industries?

- What are the driving forces stressing the implementation of cost-effective energy efficiency measures in Ghanaian industries?

- How is energy managed in Ghanaian industries? 
- How are the various information sources of energy efficient technologies valued?

This paper is unique in the sense that, to the authors' awareness, no study has so far presented results on barriers and forces driving industrial energy efficiency and studied energy management practices in Africa. Thus, the strength of this paper is in the provision of important knowledge of mechanisms and factors that influence, positively or negatively, the adoption of industrial energy efficient technologies and measures in Ghana and Africa. Even though the authors acknowledge that the results of this study cannot be generalised for all African countries, the study at least provide a good foundation for further studies in Africa.

\subsection{Overview of the industrial sector in Ghana}

Ghana's industrial sector contributed about 25.9\% of the nation's GDP in 2011 (Ghana Statistical Service) and yielded a net value of about US\$ 9.5 billion ${ }^{2}$ (World Bank, 2013). The manufacturing subsector (especially the formal sector ${ }^{3}$ ) is considered an important engine of Ghana's socio-economic development, due to its economic linkage to the two major sectors in Ghana (i.e. Agricultural and Service sectors) (Kolavalli et al., 2012). This subsector contributed about US\$ 2.7 billion $^{2}$ of Ghana's GDP in 2011 (World Bank, 2013); (see Fig. 1) which represent about 31\% of the industrial sector's value added share (GSS, 2012). The manufacturing subsector is dominated by agriculture-related activities, including food and wood processing and textiles (Kolavalli et al., 2012). Despite the importance of the manufacturing subsector, its average growth rate (3.5\%) between 2000 and 2010 was the least among the industrial subsectors. Factors like high labour cost, high cost of raw materials, the use of obsolete and inefficient machinery, and energy related factors like unstable energy supply and hikes of energy prices have contributed to the low performance of this subsector (Kolavalli et al., 2012; CEPA, 2007). 
$<<$ Position for Figure $1>>$

The energy requirement of Ghana's industrial sector is primarily met by the supply of electricity, petroleum products and wood fuels. The predominant petroleum products used in the industries are diesel and residual fuel oil, where the latter is used as a heating fuel (EC, 2006b). The manufacturing subsector is the principal consumer of energy in the industrial sector accounting for over $70 \%$ of the sector's energy share (EC, 2006b). Most of the formal manufacturing firms are energy intensive and are highly reliant on electricity and petroleum product. The share of electricity and petroleum products used in this formal manufacturing subsector accounts for about $37-41 \%$ and 55-57\% respectively, of the total subsector's share (see Fig. 2). Wood fuel is the major fuel used in the informal manufacturing sector and its share represents about $70-80 \%$ of the subsector's total energy use. As show in Fig. 3 , the share of petroleum products and electricity use in the informal manufacturing subsector ranges between 8-15\% and 8-20\% respectively, of the subsector's total energy use.

$<<$ Position for Figure $2>>$

$<<$ Position for Figure $3>>$

The city of Tema is the hub of Ghana's industrialization and home to Ghana's largest industrial area the "Tema industrial area". This industrial area is home to well over 600 industries which include aluminium and steel smelting industries, fish and food processing industries, textile industries, chemical industries, cement factories and an oil refinery. The area is a strategic regional point because it hosts most of the high revenue earning manufacturing industries in the country. Besides, the industrial area is popularly known for its high energy enduse. This area also hosts most of the high electricity and petroleum product consuming 
manufacturing firms in Ghana (e.g. VALCO, an aluminium smelting company which until 2003 accounted for $16-17 \%$ of total national electricity consumption (EC, 2006b)). A number of studies conducted in the industrial area also indicate that the use of energy is poorly managed (ESMAP, 1992; CEPA, 2002); as such a large number of these firms exhibit high energy intensive production processes compared to similar processes in other countries (OfosuAhenkorah, 2007).

\section{Literature Review}

\subsection{Barriers to industrial energy efficiency improvement}

Though the prospects of increasing energy efficiency are vast, they are usually overlooked since the potential to implement cost effective energy efficiency solutions are either shrouded or inhibited by some critical factors. These critical factors are referred to as barriers. In this context, a barrier can be defined as a postulated mechanism that inhibits investments in technologies that are both energy-efficient and (apparently) economically efficient (Sorrell et al., 2004; Rohdin and Thollander, 2006; SPRU, 2000). In order words, a barrier comprises of all factors that either hamper the adoption of cost-effective energy-efficient technologies or slow down their diffusion in the market (Fleiter et al., 2011).

The study of energy efficiency barriers is a multi-disciplinary field with contributions from theoretical backgrounds like, neo-classical economics, organizational economics, behavioural theory and organizational theory ( $\underline{\mathrm{SPRU}, 2000})$. Based on these theories, energy efficiency barriers are broadly classified under three main categories namely Economic, Organizational and Behavioural (Psychological) barriers (Palm and Thollander, 2010; Thollander and Palm, 2012; Sorrell et al., 2004; SPRU, 2000). 
As shown in literature, the nature of these barriers vary widely depending on the technology adopted, sectors and regional conditions (SPRU, 2000; Rohdin and Thollander, 2006; Thollander and Ottosson, 2008). These variations plus the multi-disciplinary nature of barriers explain the diversity in empirical approaches to studying energy efficiency barriers. Empirical barrier studies are aimed at explaining the existence of the energy efficiency gap, by investigating how barriers exist and operate, the contexts in which they arise and the manner in which different interventions can be used to bridge the efficiency gap (SPRU, 2000). According to SPRU (2000), both theoretical and empirical approaches to studying barriers are equally important and complementary; since "empirical findings are only meaningful when linked to well-articulated theoretical framework, similarly theoretical assertions are meaningful only if they stand up to empirical scrutiny" (SPRU, 2000). However, Weber (1997) points outs that theoretical classifications of empirical barriers are not exclusive, since some barriers can have an overlapping perspective (Weber, 1997). This means that an empirical barrier can have more than one theoretical background depending on the perspective of analysis.

\subsection{Driving forces for industrial energy efficiency improvement}

A driving force might be seen as a factor that can reduce or overcome a barrier, thus in this context a driving force refers to any factor that motivates or promotes the adoption of cost effective energy efficient investments (Thollander and Ottosson, 2008). Consequently, a study of the driving force to energy efficiency outlines and gives a good insight to policy makers on factors that boost energy efficiency implementation. The rationale behind adopting or improving energy efficiency in a firm can be motivated by either internal or external forces or a 
combination of both. According to Thollander and Ottosson (2008) driving forces to energy efficiency implementation can be classified into market-related, energy policies related, as well as organizational and behavioural factors (Thollander and Ottosson, 2008).

Market-related driving forces are subject to the need for a firm to stay competitive in a market by reducing energy use. Some of the commonly cited market-related driving forces are "cost reductions resulting from lower energy use” and "threat of rising energy prices”. Both factors are associated with the need for a firm to increase dividends or secure its future dividends by reducing energy use and behaviour (de Groot et al., 2001; del Rio Gonzàlez, 2005; Thollander and Ottosson, 2008).

Government energy efficiency requirements and policy instruments (in the form of voluntary agreements, energy saving certificates, emission trading schemes, energy and emissions taxes, information dissemination, investment subsidies and tax exemptions and many more) are effective promoters of industrial energy efficiency implementation. These instruments are aimed at building capacity in energy service markets and promoting more efficient energy use (McKane et al., 2008; UNIDO, 2011).

Behavioural and organizational drivers are mainly internal factors which reflect the sustainability culture and commitments of a firm. In the advent of current strict environmental policies and increased environmental consciousness, many firms implement energy efficiency to green and boost their corporate image. Other forms of internal driving forces include "people with real ambition" which is closely linked to personal commitment of managers, "long-term energy strategies” and "environmental management systems (EMS)” (Thollander and Ottosson, 2008). 


\section{Method}

Given that there is a limited amount of literature covering industrial energy efficiency implementation in Africa, the study is aimed at contributing to this field of research by investigating the present industrial energy efficiency and management practices in Ghana. In addition, the study incorporates the investigation of barriers and drivers for industrial energy efficiency implementation in Ghana, to throw light on the rationale for both the adoption and non-adoption of cost effective industrial energy efficient technologies.

The methods used in this research are exploratory and qualitative, tailored to answer and satisfy both the aims and research questions. Information collection in this study comprises of three major parts namely: (1) a literature review of relevant theories, (barriers and forces driving energy efficiency implementation); (2) a semi-structured interview of firms within the case study (Tema industrial area); and (3) a semi-structured interview with energy efficiency stakeholders. Inspired by Yin (1994), the study regards Ghana's largest industrial area (the Tema industrial area) as a case study because, the area is a good representation of Ghana's industrial energy culture.

The selections of the firms were done at random based on the Tema Department of Factories Inspectorates list of registered companies. A total of 76 companies were visited, but due to bureaucracy and poor communication only 34 agreed to participate in the study (which represents about $45 \%$ response rate). The respondents who participated in the study were reluctant to provide vital information like the annual turnover of their firm, even when the confidentiality of the information was assured. None of the firms involved in the study had an energy manager, so the interviews were conducted with the middle managers (or technical 
directors) and engineering staffs who dealt directly with energy issues in the various firms. Fig. 4 below shows the distribution of the positions of the respondents. A total of 19 technical directors and managers, and 15 engineering staff were involved in the interview. Exactly $29 \%$ of the industries studied were steel and aluminium firms; this class of industries includes smelters, roofing sheet and angle rod manufacturers. $23 \%$ were food processing firms whiles plastic product manufacturers took about $21 \%$ of the firms; some of the plastic products produced by these firms include chairs, tables, buckets and canisters. The petrochemical and chemical firms consist of the only oil refinery in Ghana - Tema Oil Refinery, paint producers and petroleum product producers. The rest, classified as Others, consist of a cement company, two textile companies, a compact fluorescent lamp manufacturer and two paper product manufacturers; the total of which represent $18 \%$ of the total respondents (see Fig. 5 below).

$<<$ Position for Figure $4>>$

$<<$ Position for Figure $5>>$

The interview with the firms' respondents was carried in out in two sessions; in the first session, respondents were asked to describe the energy management strategies used in their respective firms; also they were asked to express their views on barriers and drivers for energy efficiency implementation. All interviews were recorded and on the average each interview took about $40 \mathrm{~min}$. In the second session, respondents were asked to fill out a structured questionnaire covering the various aspects of the study. All parts of the questionnaire except the driving force section were originally developed and empirically tested by SPRU (2000). However, slight modifications were made to the questionnaire to suit the case study. These modifications were made based on a pilot test of the original questionnaire and a review of industrial energy audits 
and surveys (e.g. ESMAP, 1992) carried out in the industrial area. The section on the driving forces was developed through a literature review of related articles including de Groot et al. (2001), del Rio González (2005), Rohdin and Thollander (2006), Rohdin et al. (2007), Ottosson and Peterson (2007), and Thollander and Ottosson (2008). The parts of the questionnaire on the implementation of energy efficiency measures and technologies, barriers to energy efficiency improvement and driving forces for energy efficiency improvement applied the use of a scale to quantify the response of the respondents. To avoid imbalance, these results were initially classified under two groups; energy intensive and non-energy intensive firms, then the average score for each response under the groups were calculated and ranked. However, there were no major distinctions in the ranking of the response between the two groups, so the results were not categorized in the outline of this paper. It should be noted that, in the quantification processes large simplifications were made by respondents, thus the result contains several perspective of issues other than the single score on ranking (Rohdin et al., 2007). Furthermore, it must also be kept in mind when drawing conclusions from these types of studies that, the respondents' answers might have some degree of bias (Thollander and Ottosson, 2008).

The semi-structured interview with the stakeholders was conducted with energy experts from two renowned energy institutes in Ghana namely, Energy Commission, Ghana (EC) and Energy Foundation, Ghana (EF). EC is a government regulatory body in charge of ensuring that both energy providers and clients manage energy in an effective and efficient manner, whiles EF is an Energy Service Company (ESCO) devoted to promoting energy efficiency in Ghana. Two energy experts were interviewed from EC and one energy expert from EF. These interviews were conducted to seek information on the current industrial energy efficiency frameworks and practices existing in Ghana. 


\section{Results}

\subsection{Barriers to industrial energy efficiency improvement}

With respect to the first research question, respondents were asked to assess the existence of cost effective energy efficiency opportunities in their firms. All the respondents affirmed the existence of an efficiency gap in their respective firms, thus providing a rationale for the existence of barriers to energy efficiency.

To complement the existence of an energy efficiency gap, respondents were asked to rate the importance of 22 barriers to energy efficiency; using a scale of 0 (not important), 0.5 (often important) and 1 (very important). Fig. 6 below represents the overall ranking of the barriers. As already established, empirical barriers can best be interpreted by using a theoretical framework; thus, Table 1 below highlights barriers considered to be important (i.e. barriers with average scoring greater than or equal to 0.5 ) by respondents and their related theoretical backgrounds.

$<<$ Position for Table $1>>$

"Lack of budget funding” was considered as the most important barrier followed by “access to capital”. These two barriers are theoretically related to “access to capital”. Most of the respondents cited a lack of access to capital internally or externally as a very important or often important inhibiting factor to the implementation of energy efficiency in their firms. 12 respondents attributed this limitation to the lack of awareness or interest by top management on issues related to energy efficiency improvements in their firms. "Other priorities for capital investment” was ranked as the third highest barrier; according to Rohdin and Thollander (2006) this barrier can theoretically be linked to hidden cost. The number of respondents who ranked 
this barrier as very important stated that energy cost was perceived to be a relatively unimportant parameter by top managers; as such their top managers tended to ignore energy efficiency investments and instead allocated capital to other production related investments.

"Technology is inappropriate at this site" and "technical risks such as risk of production disruptions" were ranked in fourth position. Six respondents claimed the heterogeneity of technology was a very important factor impeding energy efficiency improvement; one respondent in particular remarked that the performance of a motor system they had acquired was below the supplier's assured performance. Additionally, production risks and externalities associated with change of technology (due to energy efficiency improvement) were stated to be a very important barrier by five respondents.

"Lack of technical skills" and "conflicts of interest within the company" was ranked in sixth and seventh position respectively. These two barriers may be related to "imperfect information" and "split incentives” respectively. Most of the firms interviewed lacked skilled personnel to evaluate the performance of an energy efficiency technology and also operate the technology; this limitation inhibited the ability of companies to take up energy efficiency technology. The inability of the firms to also appropriate the benefits of implementing these technologies (due to the lack of skilled personnel) developed a "split incentives" between parties who stand to gain more from the implementation of energy efficiency measures and those who gain less. This inability also discouraged the uptake of energy efficiency investments in the firms.

Other hidden cost related barriers such as "lack of time or other priorities" and "cost of identifying opportunities, analyzing cost effectiveness and tendering” were ranked in eighth position. Three respondents claimed that the cost involved in contracting experts to identify and 
analyze energy efficiency opportunities were very high and as such, management normally ignored such projects. "Cost of production disruption/hassle/inconvenience” was also ranked in eighth position; most respondents noted that the disruptions and inconveniences associated with installing new technologies were often important deterrents to improving energy efficiency, especially considering the demands of customers that had to be met.

\subsection{Driving forces for industrial energy efficiency improvement}

Using a scale of 0 (not important), 0.5 (often important) and 1 (very important) respondents were asked to rate the importance of 17 driving forces. The highest ranked driving force for energy efficiency improvement was "cost reductions resulting from lowered energy use" closely followed by "threats of rising energy prices" (see Fig. 7 below). These two drivers are market related (see Table 2); the respondents pointed out that these driving forces were the most important rationale for improving energy efficiency in their firms, considering that investing in energy efficiency could protect their firms from the volatile energy prices and energy supply deficiencies in Ghana.

Respondents ranked "Energy efficiency requirements by Ghanaian government" as the third most important driver, even though there were no specific stringent laws or standards with regard to industrial energy efficiency.

Energy (efficiency) and emissions tax ${ }^{4}$ are also effective energy policy drivers used all over the world by governments to promote energy efficiency in firms. The results revealed that these driving forces were lowly ranked by respondents in ninth and thirteenth position respectively.

"Environmental company profile” and "environmental management systems" were 
ranked in seventh and eight position respectively. These organizational driving forces were highly ranked by multi-national companies and companies competing on international markets.

$<<$ Position for Figure $7>>$

$<<$ Position for Table $2>>$

\subsection{Industrial Energy management and energy efficiency technology adoption}

To draw a baseline to assess the energy management profile of the firms, respondents were asked to answer questions on their energy information systems. The results revealed that 24 firms metered their electricity use at both site and building levels, whiles the remaining metered electricity use at equipment level. The results also revealed that only six firms used monitoring and targeting schemes to manage their electricity use, whiles four of the firms had benchmarks to compare their energy use against, and only five firms had conducted energy audits within the last 10 years. These results infers that the assertion of the energy efficiency gap by respondents were mostly based on intuition, given that most of the firms had never conducted an energy audit and also had poor energy information systems. With the baseline set, participants of the questionnaire were asked questions in relation to their energy management profile.

Even though energy management can help improve levels of energy efficiency in a firm (Backlund et al., 2012), and eliminate some organizational barriers (McKane et al., 2008), the results revealed that majority of the firms studied had no standardized energy policy and management system. Only five firms had subscribed to ISO Standards (ISO 22000, ISO 9001 and ISO 14001); and out of these five firms only two firms had energy policies which formed part of their ISO 14001 subscription. Respondents from these two firms also stated that the implementation of the energy policy was not extensively applied in their firms because energy 
use was not considered as an environmental hotspot in Ghana. The study also revealed that none of the studied firms had a personnel specially assigned to manage energy, as such most of the energy issues were handled by the technical directors and middle managers.

Respondents were asked to assess the extent to which they had adopted various energy efficient technologies and measures, grouped under various categories (see Table 3), using a scale of 0 (not adopted) to 1 (extensively adopted). Table 3 below shows that electrical equipment was ranked as the highest implemented energy efficiency measure; this does not come as a surprise since most of the industries studied were highly reliant on electricity (Thollander and Palm, 2012). Power factor correction ${ }^{5}$ is one of the most cost effective measures dominantly used in Ghana. The technical director of a steel smelting firm claimed that they had extensively implemented power factor correction, which had helped reduced the firm's annual electricity bill by $5-10 \%$ since 2001 . The results also revealed that 17 firms had not implemented power factor correction; respondents attributed the non-adoption of this measure to the lack of funds or ignorance of the benefits. The avoidance of idle operation of pumps, fans conveyers and other electrical equipment is another effective means of reducing electricity consumption. However, none of the industries studied had automatic switch-off systems to turn off idle equipment. Two respondents claimed they had labels and posters on walls to prompt workers on switching off idle equipment. However, both respondents could not affirm the effectiveness of this measure because they claimed it had not reflected any significant electricity savings.

$<<$ Position for Table $3>>$

The study revealed that none of the firms had light control systems (occupancy sensors) to automatically put lights on/off when needed. Most of the firms had extensively replaced 
tungsten lamps with CFLs; the reason for this high rate of implementation was attributed the extensive promotion of CFLs by the government. Most of the firms had extensively optimized daylight by properly positioning their windows and also using skylight to reduce the use of artificial lights during the day.

To ensure optimal operation of boilers, 31 respondents claimed they accurately regulated boiler temperature, pressure, and air/fuel ratio. Only two of these respondents claimed they used boiler refractory to help reduce fuel consumption. Additionally, only one firm had a heat recovery system, which was basically used for electricity production.

The use of appropriate and efficient motors to drive compressors and pumps was a major measure implemented in 33 firms; the use of centrifuge pumps and throttle control was another measure used by the firms. The study revealed that the inspection and elimination of leaks for compressors were not being extensively applied due to the poor maintenance culture in most Ghanaian industries. Three respondents confirmed this fact by saying that most maintenance of machinery were carried out on rare occasions and only when they were faulty.

\subsection{Industrial energy efficiency information source in Ghana}

The Electricity Company of Ghana ${ }^{\underline{6}}$ (ECG) and EC are the official government bodies responsible for providing and disseminating energy efficiency information in Ghana. Other information sources include EF, trade unions, energy consultants, colleagues within firms and written sources like journals and manuals.

Participants of the study were asked to rank the effectiveness of energy efficiency information sources in Ghana. An average scoring of the response indicates that information from the electricity utility company ECG was ranked as the best source (see Fig. 8). Public utility 
companies like ECG are well positioned in the energy market to promote industrial energy efficiency in Ghana, because of their strong energy ties with customer and the technical familiarity with customer equipment. However, most of the respondents remarked that energy efficiency programs by ECG and EC were normally intensive when there is an energy crisis in the country. One respondent confirmed that during the nationwide hydro-electricity crisis in 2002, ECG organized an industrial energy efficiency sensitization exercise which included seminars and workshops. Information from suppliers of equipment was ranked as the second most effective source of information, it is important to note that, information from this source may be imperfect or asymmetric, because energy efficient equipment produced in developed countries may not suit the conditions in developing countries. Information from EF and EC were ranked in third and fourth positions respectively; energy efficiency information from EC was popular among government-owned industries, due to efforts by government to reduce electricity expenditure in these industries. Information from trade unions (or sector organization) and regional energy agency were ranked in eleventh and twelfth position respectively, representing poor sources of information. This can be explained by the fact that the industrial area had no centralized managing system and as such information sharing among firms in the industrial area was quite low.

$<<$ Position for Figure $8>>$

\section{Discussions}

\subsection{Lack of policy framework}

The results revealed that all the barriers considered to be of high importance were of economic origin (i.e. theoretically related to economic factors) (see Table 1). Furthermore all of 
these barriers except "lack of information" are rational behaviour barriers (or market barriers). According to UNIDO (2011) rational behavioural changes with regard to energy efficiency improvement are best influenced by policies with strong implementation mechanisms and regular evaluation (UNIDO, 2011). Consequently, the prevalence of rational behavioural barriers in Ghana can be explained as an indication of the lack of policy for industrial energy efficiency improvement in Ghana. In other words, the prevalence of market barriers as a consequence of the lack of policy framework for industrial energy efficiency improvement can make firms in Ghana irrationally downgrade the priority of energy efficiency implementation. As part of efforts by the Ghanaian government to promote energy efficiency, there are policy instruments which indirectly promote energy conservation in industrial firms. One of such policy is the implementation of the efficiency standards and labeling for air conditioners, refrigerators, and lamps. This policy instrument has been effective in improving energy efficiency on the support side (processes) of industries rather than the production side.

Additionally, some contextual factors in the form of heavy energy subsidies, low energy taxes, and lack of emission taxes are currently factors counteracting the improvements of industrial energy efficiency in Ghana. Ghana's regulated energy market has the government as sole controller of energy prices. As such efforts by the government to make energy affordable, attracts heavy subsidies on energy prices (particularly electricity and petroleum products). These subsidies end up distorting the real cost of energy supplied to industries and in effect sends the wrong price signal to the industries. As it is well proven, higher energy prices are associated with significantly higher rates of adoption of industrial energy efficient equipment (UNIDO, 2011). Thus, the highly subsidized industrial energy prices in Ghana motivates little efficiency improvements in this sector. The study of driving forces for improving energy efficiency 
revealed that "energy tax" and "emission tax" were lowly ranked (in 9th and 13th position respectively). This result emphasizes the negative impact of the low industrial energy prices on industrial energy improvement in Ghana. Notably, the driver results also revealed that the 2nd highest ranked driving force is also related to energy price signals (threats of rising energy prices); this point highlights the need for government to price energy in a competitive manner to promote industrial energy efficiency.

Voluntary agreements have proven to be an effective alternative to mandatory policy instruments especially in developing countries where there are low compliance to laws and nonexistence of strict energy and environmental laws. The lack of such a policy instrument in Ghana explains it being ranked as the lowest driving force.

\subsection{Lack of access to funds}

As highlighted in the results, the two highest ranked barriers are related to financial limitations; this revelation spells out the importance of access to funds to the improvement of energy efficiency in Ghana. The highest mentioned barrier is "lack of budgeting"; most of which respondents attributed to the lack of interest by the top management to improve energy efficiency. As such energy efficiency investments are not given priority by top management. Access to external funding for improving energy efficiency in the form of loans was a major barrier mentioned by most of the respondents. One shortfall in Ghana associated with access to external funding is the lack of technical capacity and experience of banks or financial institutes to properly evaluate credit worthiness of firms and risks associated with energy efficiency projects; this eventually results in the declination of loans for viable energy efficiency projects. 
Another shortfall is the high interest rate on loans in Ghana which deter most industries from going in for loans to undertake energy efficiency projects. This fact was affirmed when two respondents said that, top management in their firms were reluctant to borrow money to fund energy efficiency projects because of the high interest rate and the uncertainties associated with such projects.

\subsection{Lack of management awareness}

Regardless of the high awareness of energy management and efficiency improvement among respondents (technical directors and middle managers), most of the respondents confirmed that the level of awareness among top managers in Ghana, was generally low. This low awareness level (among top managers) was reflected in the poor energy culture and energy management of the industries and a root for some of the highly ranked barriers. From the barriers results "other priorities for capital investment” was considered as a very important barrier (ranked in third place); this ranking partly stemmed from the low awareness level among top managers. The low awareness results in top management perceiving energy efficiency improvement issues as secondary to other investments. A respondent (manager) remarked that top management in his firm would rather allocate funds for energy equipment like electricity generator (to ensure reliable supply of electricity), than invest in energy efficiency equipment. The rationale for this position by top management is linked to the perceived risks associated with energy efficiency equipment (i.e. risk of production disruptions and heterogeneity of technology) and the ignorance of top management to the benefits of energy efficiency investments. Most of the respondents (especially the middle managers and technical directors) confirmed that the lack of awareness of energy efficiency by top management was also a critical factor inhibiting their efforts to improve 
energy efficiency; this contributed to the high ranking of "conflict of interest within the company”. This conflict emanated from a split in incentives, where top managers were more focused on increasing production and profits rather than reducing energy cost or emissions. The lack of awareness among top management can also be associated with other low ranked barriers like “lack of staff awareness” and "low priority given to energy management”.

\section{Conclusions}

The results from the energy management part of the questionnaires shows that energy is poorly managed in the Tema industrial area; with a low implementation of cost effective energy efficient technologies in the respective firms studied. This low implementation principally stems from a combination of market barriers linked to the lack of government frameworks for industrial energy efficiency improvement in Ghana. More so, the results revealed that majority of the firms studied had neither a standardized energy policy nor an energy management system. An analytical generalization of these results depicts the fact that Ghana has a vast industrial energy efficiency gap considering the low implementation of the energy efficiency measures in the case study.

Additionally, the paper shows that respondents identified internal and external limited access to funds as the most important obstacle preventing energy efficiency improvements. Internal access to funds is limited by the low awareness of top management to energy efficiency improvement measures which in effect results in energy efficiency investments being given a low priority. External access to funds on the other hand is limited by high interest rates associated with loans from banks and financial institutes. These facts underscore the importance 
of finding means, such as energy policy instruments based on providing financial supports or incentives to overcome these barriers in Ghanaian industries.

According to the respondents, market related driving forces like "cost reductions resulting from lowered energy use" and "threats of rising energy prices" are the most important promoters for implementing energy efficiency measures or technologies. "Government efficiency requirements" is another important energy efficiency promoter highlighted by respondents; this particular finding is unique given that it is not high-ranked in any previous studies from developed countries, (e.g. de Groot et al., 2001; del Rio Gonzàlez, 2005; Rohdin et al., 2007; Thollander and Ottosson, 2008); this outcome can partly be linked to standards and labelling scheme for air conditioners, refrigerators and lamps introduced by the Ghanaian government.

The result from energy information sources reveals that Ghanaian industries place high credibility in the power companies (ECG). The study also reveals that information dissemination geared towards increasing industrial energy efficiency is generally very low among top managers; the study also shows that public campaigns to increase the awareness of industrial energy efficiency and management are mostly intensified when there is an energy crisis in the country. The provision of technical and financial support by government bodies (like the EC) to improve energy efficiency in industries are mostly limited to only government owned firms; this is due to lack of adequate government funding to extend it to private own firms.

This paper represents a pioneering study revealing factors promoting and inhibiting energy efficiency improvements in Ghanaian industries. The study presents a good insight for future policies and government intervention towards industrial energy efficiency improvements in Ghana and lays a foundation for further studies in Africa. However, the authors recommend 
that further studies should incorporate views of external stakeholders like researchers, equipment dealers, financial organizations, local government, trade associations/unions and many more to develop a broad base knowledge more suitable for policy implementations.

\section{Acknowledgement}

The work was made possible thanks to funding from Ångpanneföreningens Forskningsstiftelse (ÅForsk). We respectfully acknowledge the assistance of the Tema Metropolitan Director of Factories Inspectorates and all respondents of the study for giving freely their time and effort.

\section{References}

Backlund, S., Thollander, P., Palm, J., Ottosson, M., 2012. Extending the energy efficiency gap. Energy Policy 51, 392-396.

CEPA (Center for Policy Analysis, Ghana), 2002. Energy Intensity Survey. Retrieved January 20, 2013 from http://www.cepa.org.gh/researchpapers/Research-Findings-from-EnergyIntensity-Survey-of-the-Modern-S64.pdf

CEPA, 2007. The Energy Crisis and Growth Performance of the Economy. Selected Economic Issues No. 15. CEPA, Accra.

Compton, M., 2011. Industrial energy efficiency in developing countries: A background note. Unite Nation Industrialization Development Organization, Vienna. Retrieved August 19, 2012

from http://www.unido.org/fileadmin/user_media/Services/Research_and_Statistics/WP03201 


\section{1_Ebook.pdf}

de Groot, H., Verhoef, E., Nijkamp, P., 2001. Energy saving by firms: Decision-making, barriers and policies. Energy Economics, 23(6), 717-740.

del Rio Gonzàlez, P., 2005. Analysing the factors influencing clean technology adoption: A study of the Spanish pulp and paper industry. Business Strategy and the Environment, 14(1), 20-37.

EC (Energy Commission, Ghana), 2006a. Strategic National Energy Plan 2006 - 2020. Main report. EC, Accra.

EC, 2006b .Strategic National Energy Plan 2006 - 2020, Annex One of Four, Energy Demand Sectors of the Economy. EC, Accra.

ESMAP (Energy Sector Management Assistance Programme), 1992. Ghana: Industrial Energy Efficiency Activity. Main Report Phase 1 November, 1992: Report No. 148A92. Retrieved January $\quad 20, \quad 2013 \quad$ from $\quad \underline{\text { http://www- }}$ wds.worldbank.org/external/default/WDSContentServer/WDSP/IB/1999/08/15/00000926 5396103190015/Rendered/PDF/multi_page.pdf

Fleiter, T., Worrell, E., Eichhammer, W., 2011. Barriers to energy efficiency in industrial bottom-up energy demand models. Renewable and Sustainable Energy Review 15, 30093111.

GSS (Ghana Statistical Service), 2012. National Accounts Statistics: Gross Domestic Product Fourth Quarter 2011. GSS, Accra. 
Golove, W. H., Eto, J. H., 1996. Market Barriers to Energy Efficiency: A Critical Reappraisal of the Rationale for Public Policies to Promote Energy Efficiency. Lawrence Berkeley Laboratory, Berkeley. Retrieved July 2, 2012 from http://eetd.lbl.gov/EA/EMP/reports/3809.pdf

Hirst, E., Brown, M., 1990. Closing the efficiency gap: barriers to the efficient use of energy. Resources, Conservation and Recycling 3, 267-281.

IPCC, 2007. Contribution of Working Group III to the Fourth Assessment Report of the Intergovernmental Panel on Climate Change. Summary for Policymakers. Retrieved June 8, 2012 from http://www.ipcc.ch/SPM040507.pdf.

Kolavalli, S., Robinson, E., Diao, X., Alpuerto, V., Folledo, R., Slavova, M., Ngeleza, G.K., Asante, F., 2012. Economic Transformation in Ghana: Where Will the Path Lead? International Food Policy Research Institute, Washington. Retrieved February 2, 2012 from http://www.ifpri.org/sites/default/files/publications/ifpridp01161.pdf.

McKane, A., Price, L., de la Rue du Can, S., 2008. Policies for promoting industrial energy efficiency in developing countries and transition economies. Unite Nation Industrialization Development Organization, Vienna. Retrieved June 20, 2012 from http://www.unido.org/fileadmin/media/documents/pdf/Energy_Environment/ind_energy_ efficiencyEbookv2.pdf

MoEn (Ministry of Energy Ghana), 2010. National energy policy 2010. Retrieved January 21, 2013 from http://ghanaoilwatch.org/images/laws/national_energy_policy.pdf 
MoEn, 2011. Energy Statistics in Ghana: Facts and figures. Ministry of Energy Ghana Publication Department, Accra.

Ofosu-Ahenkorah, A. K., 2007. Potential for Energy Savings, In: Energy Crisis in Ghana: Drought, Technology or Policy? Kwame Nkrumah University of Science and Technology, Ghana, pp. 16-33.

Ottosson, C., Peterson, K., 2007. First results from the Swedish LTA programme for energy efficiency in industry. Paper presented at the 2007 European Council for an EnergyEfficient Economy (ECEEE) summer study “Saving energy - just do it”, Panel 7, 15171525.

Palm, J., Thollander, P., 2010. Interdisciplinary perspective on industrial energy efficiency. Applied Energy 87(10), 3255-3261.

SPRU (Science and Technology Policy Research), 2000. Reducing barriers to energy efficiency in public and private organizations. Brighton, UK.

Sorrell, S., O'Malley, E., Schleich, J., Scott, S., 2004. The economics of energy efficiency Barriers to cost-effective investment. Edward Elgar, Cheltenham.

Thollander, P., Ottosson, M., 2008. An energy-efficient Swedish pulp and paper industry exploring barriers to and driving forces for cost-effective energy efficiency investments. Energy Efficiency, 1 (1), 21-34. 
Thollander, P., Palm, J., 2012. Improving energy efficiency in industrial energy systems: An interdisciplinary perspective on barriers, energy audits, energy management, policies, and programs. Springer, London.

Trianni, A., Cagno, E., Thollander, P., Backlund, S., 2012. Barriers to industrial energy efficiency in foundries: a European comparison. Journal of Cleaner Production 40 (2), $161-176$.

Rohdin, P., Thollander P., 2006. Barriers to and driving forces for energy efficiency in the nonenergy intensive manufacturing industry in Sweden. Energy 31, 1836-1844.

Rohdin, P., Thollander P., Solding P., 2007. Barriers to and drivers for energy efficiency in the Swedish foundry industry. Energy Policy 35, 672-677.

UNIDO (Unite Nation Industrialization Development Organization), 2011. Industrial energy efficiency for sustainable wealth creation: Capturing environmental, economic and social dividends.UNIDO, Vienna.

Weber, L., 1997. Some reflections on barriers to the efficient use of energy. Energy Policy (25), 833-835.

World Bank, 2013. Ghana national accounts data. Retrieved January 21, 2013 from http://databank.worldbank.org/ddp/editReport?REQUEST_SOURCE=search\&CNO=2\& $\underline{\text { country }=\text { GHA \&series }=\text { \&period }}$

Yin, R. K., 1994. Case Study Research: Design and Method. Applied Social Research Methods, Vol. 5. Sage Publications, London. 


\section{List of Figures}

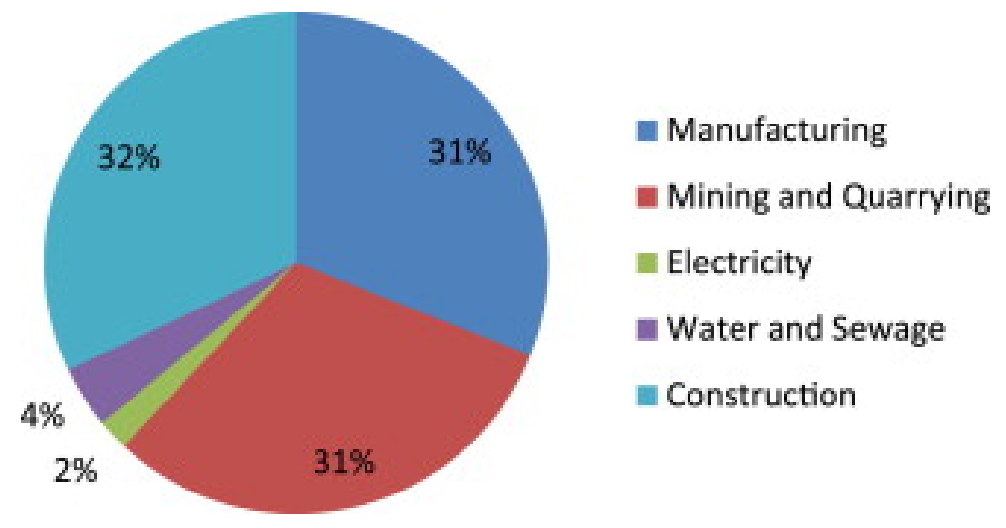


Fig. 1: Share of each industrial sub-sector from the total GDP produced by industrial sector in 2011(GSS, 2012)

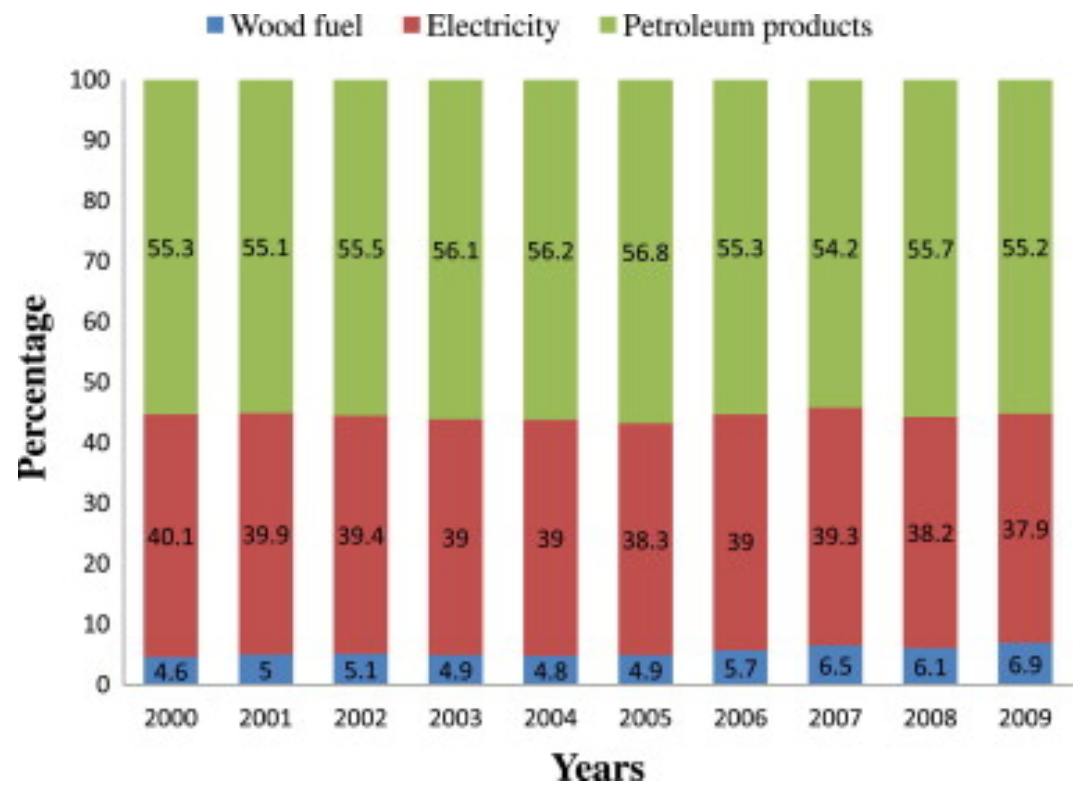

Fig. 2: Formal manufacturing subsector fuel share 2000-2009 (MoEn, 2011)

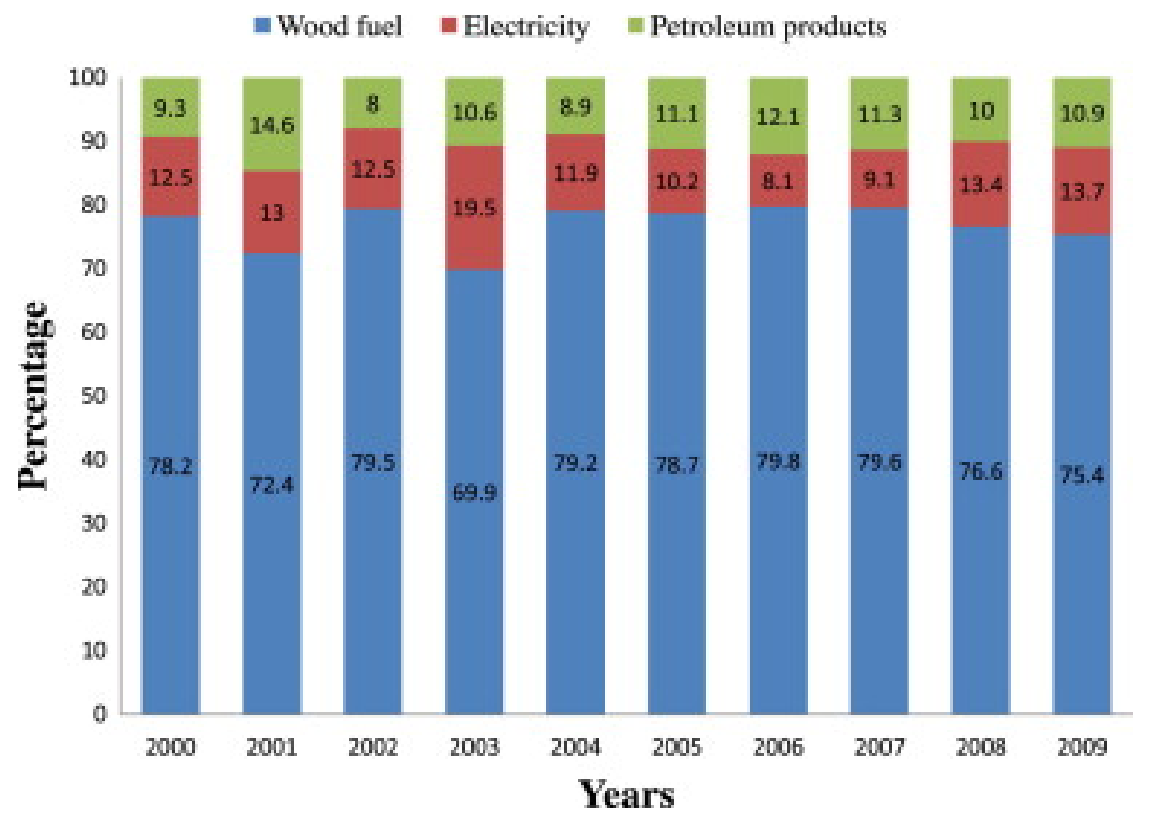

Fig. 3: Informal manufacturing subsector fuel share 2000-2009 (MoEn, 2011) 

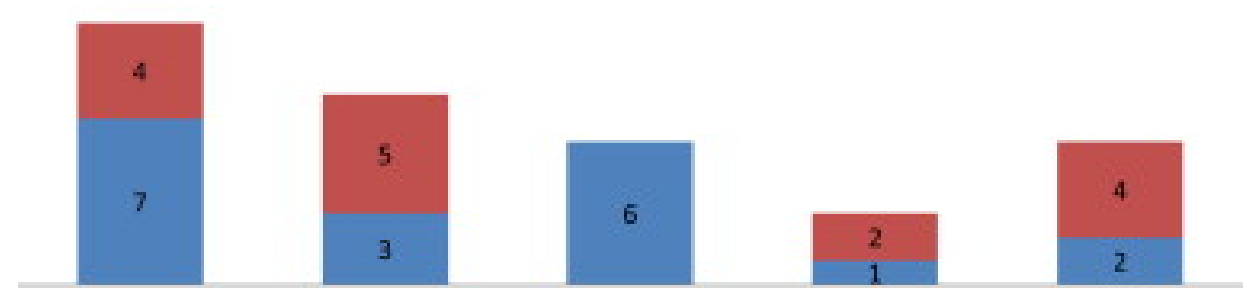

Steel and

Food processing Plastic products

Aluminum

Petrochemicals

Other and chemical

Fig. 4: Participating Industrial Sectors

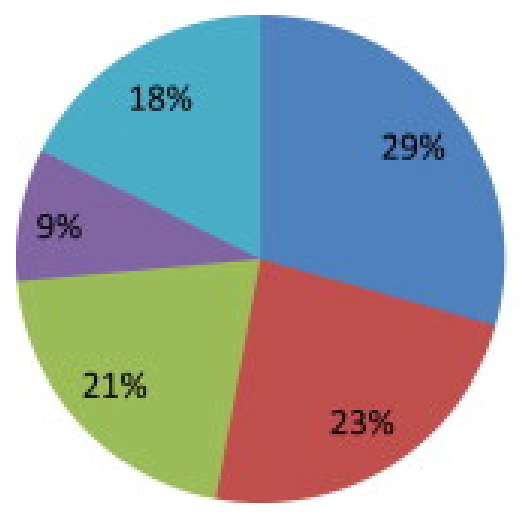

\author{
- Steel and Aluminium \\ - Food processing \\ Plastic products \\ Petrochemicals and chemical \\ Other
}

Fig. 5: Distribution of Position of Respondents

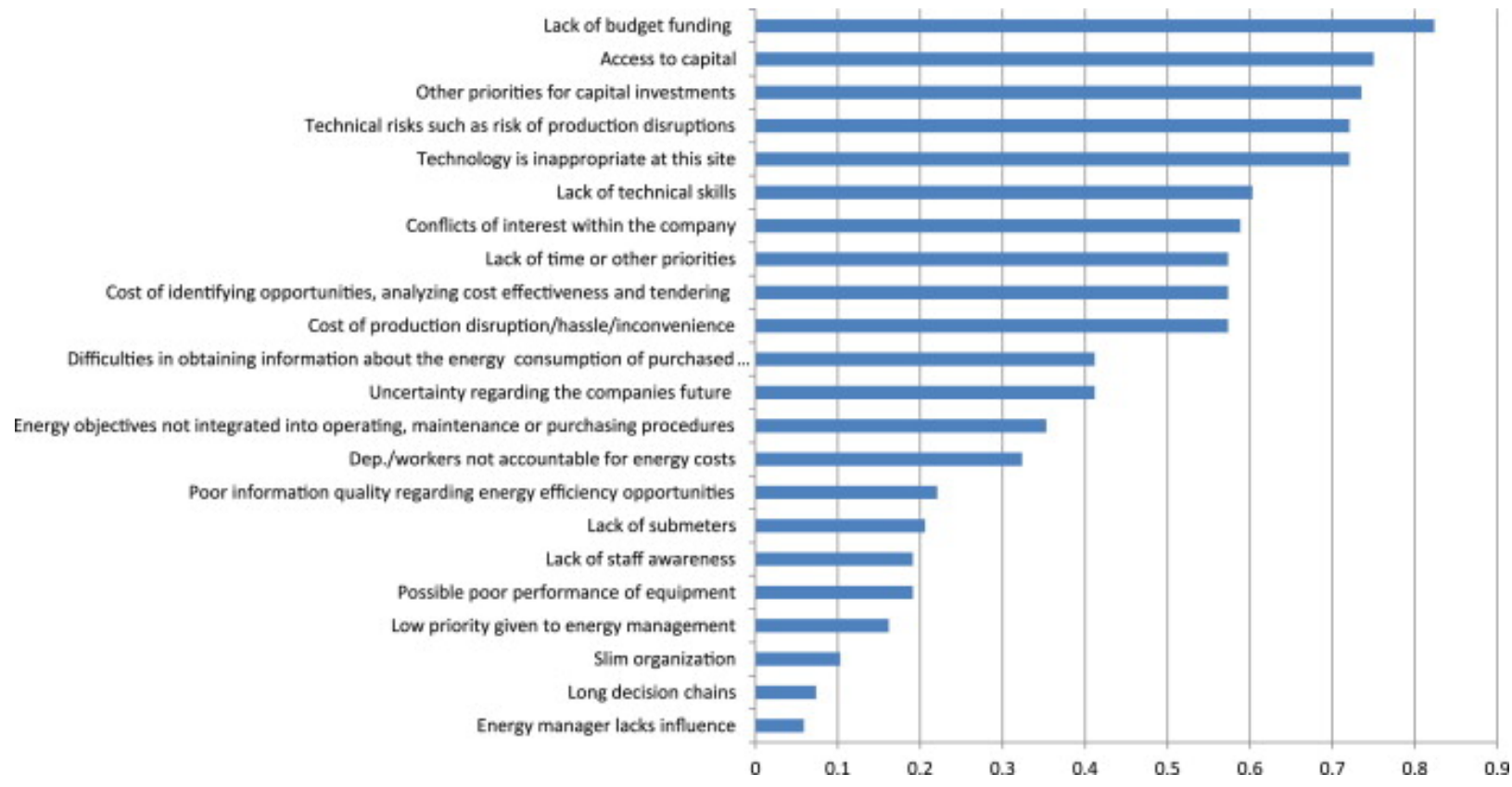


Fig. 6: Ranking results of barriers to improving energy efficiency

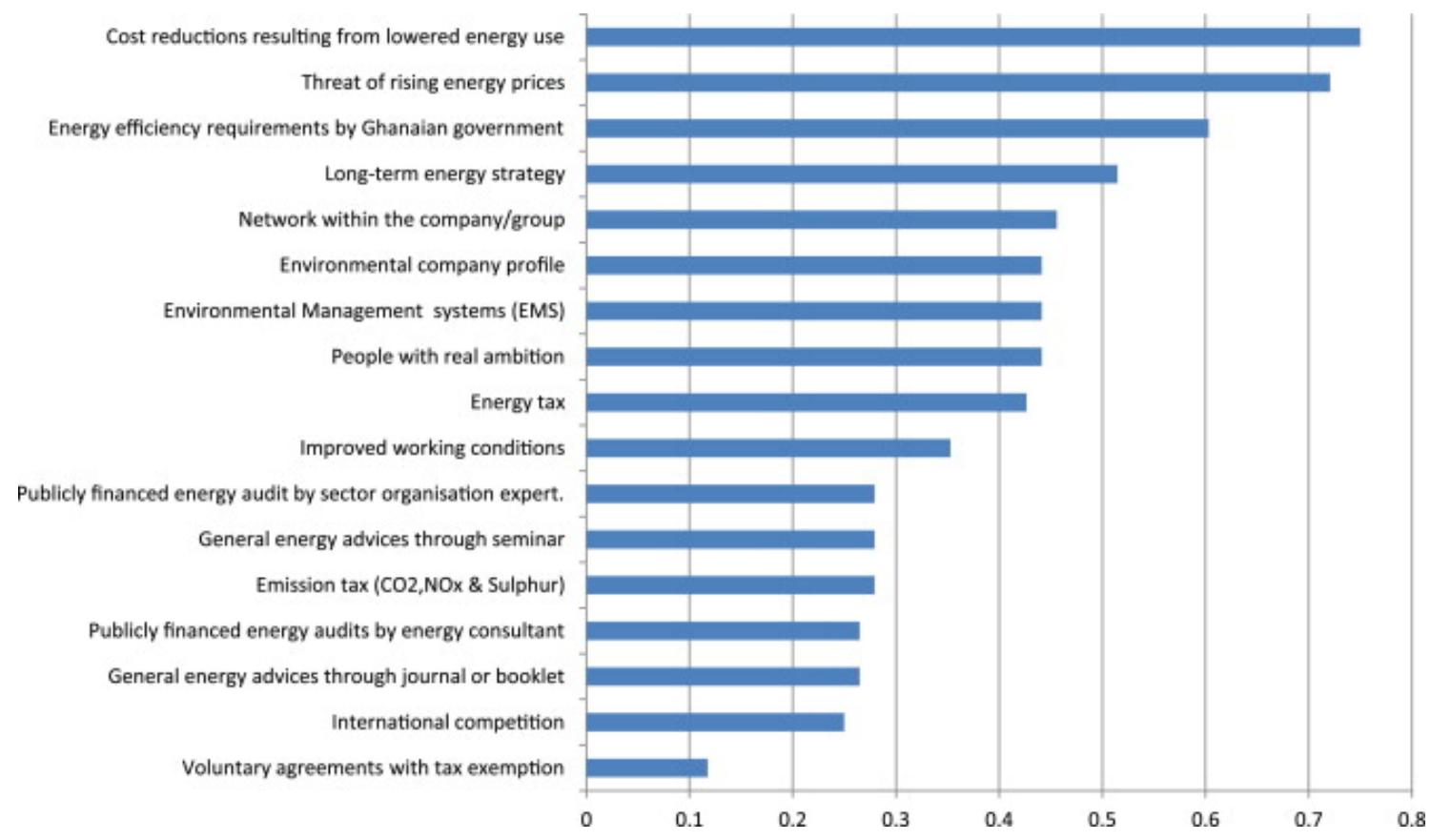

Fig. 7: Ranking of driving forces for improving energy efficiency improvement

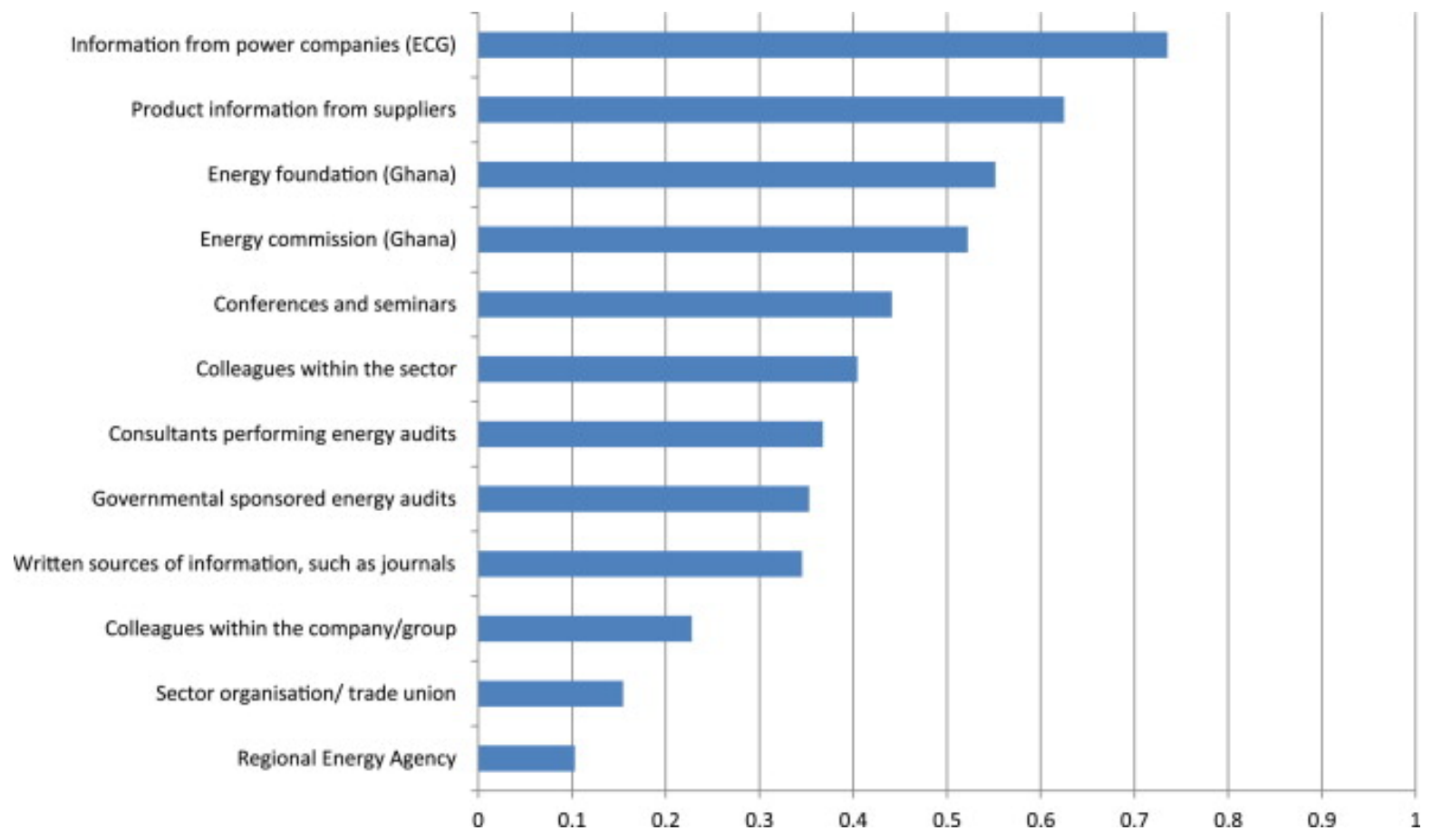


Fig. 8: Ranked results (from questionnaire) of energy efficiency opportunities information sources ( $1 \mathrm{p}$ for excellent, $0.75 \mathrm{p}$ for good, $0.5 \mathrm{p}$ for average, $0.25 \mathrm{p}$ for poor and $0 \mathrm{p}$ do not use)

\section{List of Tables}

Table 1: Classification of important barriers to energy efficiency

\begin{tabular}{|r|l|l|}
\hline \multicolumn{1}{|l|}{ Ranking } & Empirical barrier & $\begin{array}{l}\text { Related } \\
\text { theoretical barrier }\end{array}$ \\
\hline 1 & Lack of budget funding & Access to capital \\
\hline 2 & Access to capital & Access to capital \\
\hline 3 & Other priorities for capital investments & Hidden costs \\
\hline 4 & Technology is inappropriate at this site & Heterogeneity \\
\hline 4 & Technical risks such as risk of production disruptions & Risk \\
\hline 6 & Lack of technical skills & $\begin{array}{l}\text { Imperfect } \\
\text { information }\end{array}$ \\
\hline 7 & Conflicts of interest within the company & Split incentives \\
\hline 8 & Cost of production disruption/hassle/inconvenience & Risk \\
\hline 8 & $\begin{array}{l}\text { Cost of identifying opportunities<comma }>\text { analyzing cost effectiveness } \\
\text { and tendering }\end{array}$ & Hidden costs \\
\hline 8 & Lack of time or other priorities & Hidden costs \\
\hline
\end{tabular}

Table 2: Classification of important driving forces for energy efficiency improvement

\begin{tabular}{|r|l|l|}
\hline Ranking & Empirical barrier & Classification \\
\hline 1 & $\begin{array}{l}\text { Cost reductions resulting from lowered energy } \\
\text { use }\end{array}$ & Market related \\
\hline 2 & Threat of rising energy prices & Market related \\
\hline 3 & $\begin{array}{l}\text { Energy efficiency requirements by Ghanaian } \\
\text { government }\end{array}$ & $\begin{array}{l}\text { Energy policies related } \\
\text { factors }\end{array}$ \\
\hline 4 & Long term energy strategy & \\
\hline
\end{tabular}

Table 3: Major implemented energy efficiency measures and their corresponding average score 


\begin{tabular}{|c|c|c|}
\hline & & score \\
\hline \multirow[t]{2}{*}{ Electrical } & Power factor correction & \multirow{3}{*}{0.39} \\
\hline & $\begin{array}{l}\text { Use of energy efficient computers photocopiers } \\
\text { \& other office equipment }\end{array}$ & \\
\hline \multirow[t]{4}{*}{ Lighting } & Replacement of $38 \mathrm{~mm}$ fluorescents with $26 \mathrm{~mm}$ & \\
\hline & $\begin{array}{l}\text { Replacement of tungsten filament lamps with } \\
\text { compact fluorescents }\end{array}$ & \multirow[t]{3}{*}{0.36} \\
\hline & $\begin{array}{l}\text { Use of high frequency fluorescents in new \& } \\
\text { replacement fittings }\end{array}$ & \\
\hline & Optimize the use of natural light & \\
\hline \multirow[t]{2}{*}{$\begin{array}{l}\text { Compressor and } \\
\text { pump }\end{array}$} & Use of centrifuge pumps and throttle controls & \multirow[t]{2}{*}{0.33} \\
\hline & $\begin{array}{l}\text { Use of appropriate and efficient motors (or } \\
\text { variable speed motors) }\end{array}$ & \\
\hline \multirow[t]{4}{*}{$\begin{array}{l}\text { Heat processing and } \\
\text { boiler plant }\end{array}$} & $\begin{array}{l}\text { Proper Insulation of distribution pipes valves } \\
\text { and boiler. }\end{array}$ & \multirow{4}{*}{0.17} \\
\hline & $\begin{array}{l}\text { Accurate control of furnace temperature } \\
\text { pressure and air/fuel ratio }\end{array}$ & \\
\hline & Use of boiler refractory & \\
\hline & Installation of thermostatic radiator valves & \\
\hline
\end{tabular}

